\title{
How Does Bilateral Preference Affect Shared Parking in Sharing Economy?
}

\author{
Yuxue Zhang, ${ }^{1}$ Haoyu Wen $\mathbb{D}^{1}{ }^{1}$ Ming Zhao, $^{2}$ and Zhaojun Yang ${ }^{1}$ \\ ${ }^{1}$ School of Economics and Management, Xidian University, Xi'an 710071, China \\ ${ }^{2}$ Department of Information, Xi'an Vehicle Parking Service Center, Xi' an 710000, China
}

Correspondence should be addressed to Haoyu Wen; hywen@xidian.edu.cn

Received 24 December 2019; Revised 5 March 2020; Accepted 13 April 2020; Published 28 July 2020

Guest Editor: Davide Castellano

Copyright ( 2020 Yuxue Zhang et al. This is an open access article distributed under the Creative Commons Attribution License, which permits unrestricted use, distribution, and reproduction in any medium, provided the original work is properly cited.

Sharing economy is seen as an essential building block for sustainability. Yet, inefficient utilizing of parking spaces needs more attention, by which both direct and indirect traffic congestions may be caused, jeopardizing the economic potential of sustainable development. Conventional parking service may gradually lose favour in analogy to its counterpart, of which a novel approach solving shortage of urban parking resources is offered by shared parking. Hence, in this paper, problems of how to redistribute the available private-owned parking slots that be shared are focused due to the parking slot location properties that can be labelled as random, disordered, unstable, widely distributed, etc. Specifically, shared parking greatly enhances reasonability by considering satisfaction. Based on the mechanism of time matching between supply and demand, this paper thoroughly takes the bilateral preference of both parking demanders and parking space suppliers into account in terms of maximization of the utilization rate of shared parking spaces as well as the satisfaction of parking demanders, in which a multiobjective optimization model is established and the weighted sum method combined with the Hungarian method is adopted. Compared with the first-come-first-served (FCFS) strategy, the performance of the proposed method enjoys more advantages in utilizing shared parking spaces and in satisfying parking demanders. The model established and algorithm conducted in this paper meet the requirements induced by parking space redistribution in which inequalities exist between supply and demand, facilitating automobile parking and realizing higher efficiencies in using public resources regarding shortage of parking spaces in urban areas.

\section{Introduction}

Transportation is a representative of energy-dependent industry which results in excessive energy consumption and environmental pollution. Under energy and environment pressures, how to alleviate shortage of parking resources without occupying too much space poses a serious challenge for transportation [1]. At present, the number of registered automobiles in China skyrocket as the economy develops [2]. Statistics of the Traffic Management Bureau [3] showed that, in China, there are 66 cities with the number of cars exceeding 1 million until June 2019. However, the rapid increasing of cars has brought too much inconvenience due to most cities' inability to supply adequate parking spaces. Taking Beijing as a typical example, according to the 2019 Beijing Traffic Development Annual Report [4], the shortage of the parking lots was up to 1.37 million. The public and private belonging property of the parking space, together with the imbalance between parking space supply and demand, determines the scarcity of the available parking slots; hence, underutilization of existing parking spaces $[5,6]$ should be restored to its expected level, which helps alleviate the serious shortage of parking resources [7].

Owing to the severe imbalance between supply and demand of parking spaces, to which the major component is composed of private-owned ones, urban residents have to face great inconveniences and even difficulties when parking cars. For many cities, contradiction between creating more parking spaces and finite resources has become the inescapable problem, to which enormous increase in financial expenditure may not help within a short period of time. Under such circumstances, improving the utilization rate of 
public- and private-owned parking spaces seems a better alternative regarding the scarcity of parking resources $[8,9]$, of which can be summarized as the motivations of this research.

Therefore, the scheme of shared parking is rendered as acceptable to alleviate inconveniences and difficulties of parking [10]. However, despite some public-owned parking spaces which cannot be taken into consideration by the scheme at present, redistributing and matching the available private-owned shared parking spaces which locate in residential communities may encounter complicated situations due to the parking spaces' position and distribution, to which more attention should be paid. Hence, the sharing and redistributing of private-owned parking spaces is prioritized in accordance with their properties. In this study, problems regarding how to redistribute private parking slots in terms of bilateral preference under shared parking management are incorporated accordingly, thereby approaching this problem by an optimization algorithm.

The rest of the paper is organized as follows. An overview of the related issues is performed in Section 2, followed by problem description (including the shared parking scene and notations) in Section 3. Section 4 will present the parking time matching model considering bilateral preference with an algorithm designed to solve it. Numerical experiments are conducted in Section 5. Conclusions and further research directions are given in Section 6.

\section{Related Work}

Some scholars, foreign and domestic, have verified the feasibility and effectiveness of shared parking from multiple perspectives [11, 12]. Stin and Resha [13] analyzed the potential of shared parking for different purposes of building facilities and explored the feasibility of building shared parking lots. Liu et al. [14] found out that it is efficient for traffic management to reserve parking through parking permits distribution and trading. What's more, appropriate combination of reserved and unreserved parking spots can temporally relieve traffic congestion at the bottleneck and reduce the total system cost. Xiao and $\mathrm{Xu}$ [15] proposed a fair recurrent double auction mechanism and thought it plays an important role in promoting shared parking. Therefore, not only can the quantity of car trips be curbed by promoting appropriate parking spaces [16] but also the congestions be alleviated from road traffic networks by adopting the scheme of shared parking, not to mention the reduction in carbon emissions.

In researching shared parking matching strategy, Shao et al. [17] studied parking models of parking lots adopting both same and different available time and proposed a simple model for residents and public users to share parking spaces in residential areas. Cai et al. [18] researched the shared parking strategy of public-owned parking lots and proposed a network-based parking space allocation method. Kong et al. [19] proposed a parking matching method for intelligent parking space sharing, distribution, and pricing, which is based on IoT/cloud technology architecture and on the auction perspective. Hao et al. [20] studied the floating charging method of shared parking.
Most of the existing researches concerning shared parking focused on the following three factors, namely, the analysis of the feasibility of shared parking, the construction of shared parking allocation model, the design of third-party shared parking platform [21]. Yet, few matching research literatures brought to light the exclusive scarcity of shared parking spaces and the distinctive characteristics of parking demanders, which can be specifically classified as the bilateral preference (including demanders' and supplies' preferences), the matching and redistributing of shared parking in residential communities, the time that shared parking spaces cost in the same period, and the number of parking demanders.

The research objects are therefore sketched as residential area-located parking demanders who are featured with multiple parking demands and sharable parking spaces in multiple sharable periods. This paper considers shared parking space preference (parking space utilization) and parking demanders preferences (such as walking distance after parking, parking fees, and safety) in terms of redistributing and matching time of both shared private parking space and parking demanders. Accordingly, the preference is divided into three terms by the shared parking platform with regard to the different expressions of the parking preference, including clear numbers, interval numbers, and language term preference, which maximizes the utilization of shared parking spaces and the satisfaction degree of parking demanders. The key contributions of this paper can be recapitulated as constructing a multiobjective optimization model for shared parking in terms of bilateral preference, to which a relevant algorithm is designed. Shared parking is formulating its tendency throughout the developing process of the sharing economy. Our work will be reasonable for policymakers and business supervisors who wish to satisfy users' experience of parking.

\section{Problem Description}

In this section, the shared parking scene for matching parking demanders with parking suppliers is sketched. Related notations are therefore defined to denote the sets and variables included.

3.1. Description for Shared Parking Scenario. In specific cases with finite parking spaces in public parking areas, there is a partial overflow parking seeker. Parking spaces located in residential areas within a certain distance around the public parking area can provide shared parking spaces due to the tidal effect. Such parking spaces are identified as shareable parking spaces. According to the different use of the land properties, the shared parking with maximum satisfaction refers to the parking space allocation that maximizes the preference of the supply and demand by implementing the different time sharing [13]. The satisfaction degree is calculated according to the bilateral preference. The parking space allocation is assumed to be within walking distance of the public parking area (studies showed that 95\% of users can accept a maximum walking distance of $350 \mathrm{~m}$ after parking) [22]. The residential area provides $n$ shared parking 
space. Among the parking demanders in the public parking area, there are $m$ drivers who reserve the use of shared parking spaces.

In the study of the simulated shared parking scenario, we set the following definitions with explanations: an owner of the shared parking space is identified as a "supplier," whilst a parking demander is regarded as a "demander" and two types of participants are connected through a "shared parking platform." Therefore, the shared parking scenario can be identified as follows (as shown in Figure 1): the shared parking platform connects two types of participants together, including suppliers and demanders. The suppliers would like to submit the information of the shared parking space to the platform, including shareable time and location, whilst the demanders are also submitting their information (parking time and the expected value of the parking space attributes) to the parking platform, wishing to obtain slots for parking. The parking platform returns the corresponding feedbacks (matched participants and priority attributes) to participants. It is emphasized that each round of allocation is closely connected with the former allocations, since the previous records (participants' participation times, compliance, and matched result) are combined with allocation result before the final feedbacks in each round can be concluded.

3.2. Notations. In order to describe the matching problem between the shared parking space and the parking demanders, the following symbols are used in this paper:

$D=\left\{D_{1}, D_{2}, \ldots, D_{m}\right\}$ : a set of $m$ parking demanders, where $D_{i}$ denotes the $i_{\text {th }}$ parking demanders, $i=1,2, \ldots, m$.

$P=\left\{P_{1}, P_{2}, \ldots, P_{n}\right\}:$ a set of $n$ shared parking spaces, where $P_{j}$ denotes the $j_{\text {th }}$ shared parking spaces, $j=1,2, \ldots, n$.

$t_{i}^{a}, t_{i}^{b}$ represent the expected arriving and leaving time of the $i_{\text {th }}$ owner at the parking space, respectively.

$a_{j}^{s}, a_{j}^{e}$ are the starting and ending moments at which the $j_{\text {th }}$ parking space can be shared.

$b_{s}, b_{e}$ represent the start and end time of a shared parking space during a certain time period (such as $0-24$ as the time period involved in the model). $b_{s} \leq \forall a_{j}^{s}, b_{e} \geq \forall a_{j}^{e}$ are set to discretize the time segment. $C=\left\{C_{1}, C_{2}, \ldots, C_{q}\right\}$ : a set of $q$ attributes for evaluating the parking space, where $C_{g}$ denotes the $g_{\text {th }}$ attribute, $g=1,2, \ldots, q$. Here, the attributes are considered in three formats, crisp number (such as parking fee), interval number (such as walking distance after parking), and linguistic terms (such as parking safety). The crisp number can be regarded as a special interval number with the same upper and lower limits. Let $C=$ $\left\{C^{C}, C^{I}, C^{L}\right\}$ be a set of attribute subsets, where $C^{C}, C^{I}, C^{L}$ denote the attribute values in the formats of crisp number, interval number, and linguistic term, respectively, $C^{C} \cap C^{I}=\varnothing, C^{C} \cap C^{L}=\varnothing, C^{I} \cap C^{L}=\varnothing$.

$E=\left[e_{i g}\right]_{m \times q}:$ a decision matrix for the aspiration level of parking demanders, where $e_{i g}$ denotes the aspiration level provided by parking demanders $D_{i}$ to shared parking spaces concerning attribute $C_{g}, \quad i=$ $1,2, \ldots, m, g=1,2, \ldots, q$.

$A=\left[a_{j g}\right]_{n \times q}:$ a decision matrix for the evaluation level of shared parking spaces, where $a_{j g}$ denotes the evaluation level of shared parking spaces $P_{j}$ concerning attribute $C_{g}, j=1,2, \ldots, n ; g=1,2, \ldots, q$.

$W=\left\{w_{1}, w_{2}, \ldots, w_{q}\right\}:$ a vector of attribute weights, where $w_{g}$ denotes the weight of attribute $C_{g}$, $\sum_{g=1}^{q} w_{g}=1,0 \leq w_{g} \leq 1, g=1,2, \ldots, q$.

\section{Model Construction}

In this section, a model-based method is proposed to solve the abovementioned problem regarding private parking slot sharing. An optimization model of parking time matching is established in terms of satisfaction, under which an algorithm is designed accordingly.

4.1. Model for Matching Parking Demanders and Suppliers. The parking time is discretized during the time period involved in the model. The time interval ranging from $b_{s}$ to $b_{e}$ is divided into $T=\left(b_{e}-b_{s}\right) / \Delta T$ equal time periods (such as 0.5 hours) and each time interval is $\Delta T$. The period of the shared parking spaces can be expressed as $b_{s}+(t-1) \cdot \Delta T$ to $b_{s}+t \cdot \Delta T$, where $t=1,2, \ldots, T$.

Depending on the shareable parking period and the parking demanders period provided by the shared parking space, $d_{i j}$ is used to indicate the relationship between the rental period of shared parking space and the parking demanders period:

$$
d_{i j}= \begin{cases}0, & \left(t_{i}^{a}, t_{i}^{d}\right) \in\left(a_{j}^{s}, a_{j}^{e}\right), \\ 1, & \left(t_{i}^{a}, t_{i}^{b}\right) \notin\left(a_{j}^{s}, a_{j}^{e}\right), \\ & i=1,2, \ldots, m, j=1,2, \ldots, n .\end{cases}
$$

By analyzing whether there is an intersection of the parking time windows for different vehicles, it can be judged whether different vehicles can be allocated to the same parking space within the available time provided by the shared spaces so that $p_{i r}$ represents the relationship of different vehicle reservation time:

$$
p_{i r}= \begin{cases}1, & \left(t_{i}^{a}, t_{i}^{d}\right) \cap\left(t_{r}^{a}, t_{r}^{d}\right) \neq \varnothing \\ 0, & \left(t_{i}^{a}, t_{i}^{d}\right) \cap\left(t_{r}^{a}, t_{r}^{d}\right)=\varnothing \\ & i, r \in 1,2, \ldots, m\end{cases}
$$

By judging whether there is an intersection between the time of parking demanders and the time of the shared parking space, the demand column vector can be constructed as

$$
\begin{gathered}
q_{i}=\left(q_{1 i}, q_{2 i}, \ldots, q_{t i}, \ldots, q_{T i}\right)^{T} \\
i \in 1,2, \ldots, m ; t=1,2, \ldots, T
\end{gathered}
$$

where 


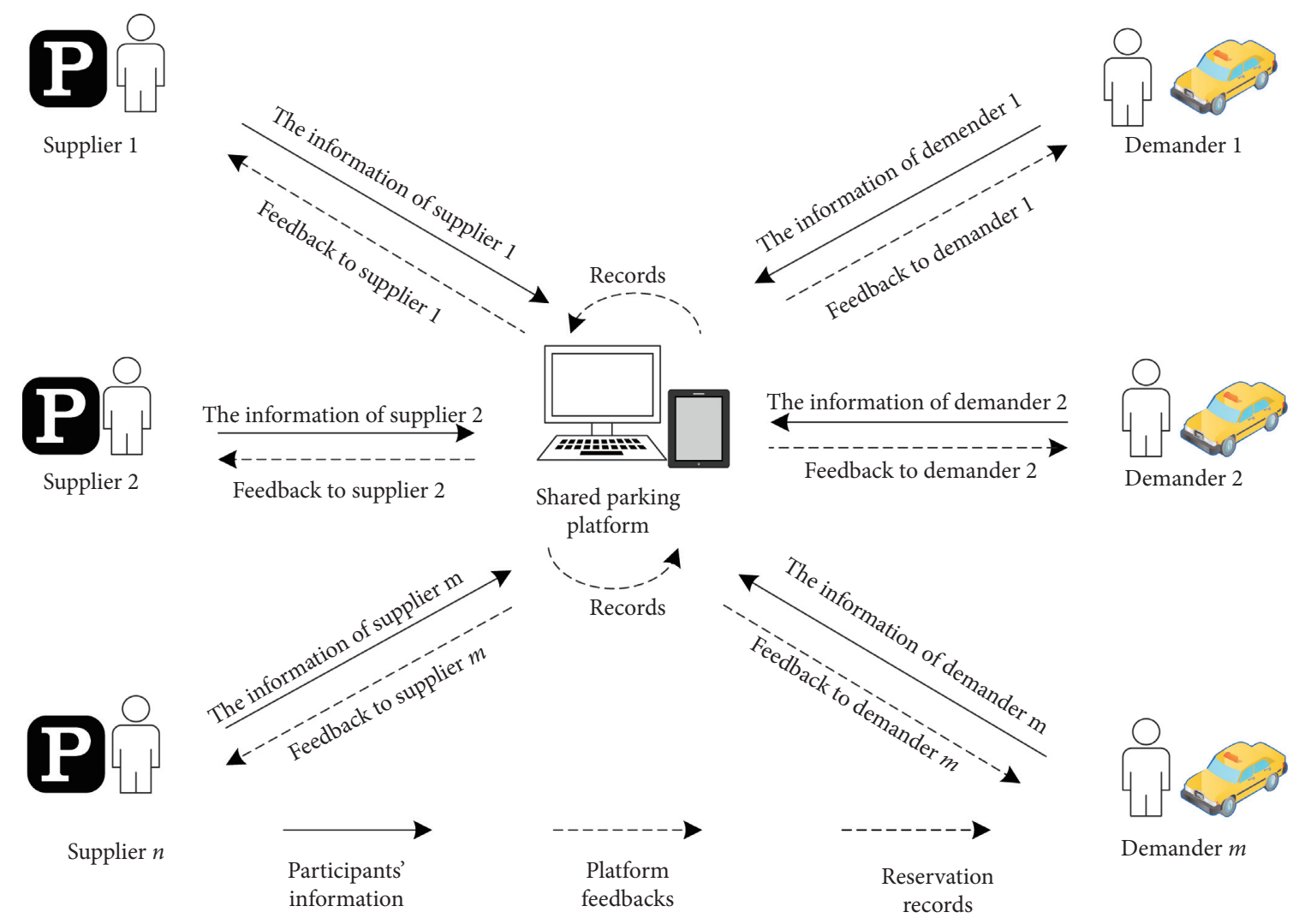

FIGURE 1: The shared parking scenario.

$$
q_{t i}= \begin{cases}1, & \left(t_{i}^{a}, t_{i}^{d}\right) \cap\left[b_{0}+(t-1) \cdot \Delta T, b_{0}+t \cdot \Delta T\right]=\varnothing \\ 0, & \left(t_{i}^{a}, t_{i}^{d}\right) \cap\left[b_{0}+(t-1) \cdot \Delta T, b_{0}+t \cdot \Delta T\right]=\varnothing \\ & i \in 1,2, \ldots, m, t=1,2, \ldots, T\end{cases}
$$

For example, $q_{i}=(0,0,1,1,0, \ldots, 1,1)^{T}$ indicates the 3 rd to 4 th time and the last two periods of the $i$ parking demanders reservation.

The decision variable $x_{i j t}$ indicates the matching between the $i_{\text {th }}$ owner and the $j_{\text {th }}$ parking space during the $t$ period, where

$$
x_{i j t}=\left\{\begin{array}{l}
1, \quad A t, \quad \text { the owner is assigned to jparking space, } \\
0, \quad A t, \quad \text { the owner is not assigned to jparking space. }
\end{array}\right.
$$

The target model $M 1$ can be built and expressed as

$$
\begin{gathered}
\max z_{1}=\sum_{i=1}^{m} \sum_{j=1}^{n} \sum_{t=1}^{T}\left(q_{t i} x_{i j t}\right) \\
\text { s.t. } \quad \sum_{j=1}^{n} x_{i j t} \leq 1, \\
\\
i=1,2, \ldots, m, t=1,2, \ldots, T \\
d_{i j}+x_{i j t} \leq 1, \quad i=1,2, \ldots, m ; j=1,2, \ldots, n ; t=1,2, \ldots, T
\end{gathered}
$$

$$
\begin{gathered}
x_{i j t}+p_{i r} x_{r j t} \leq 1, \quad i, r=1,2, \ldots, m, j=1,2, \ldots, n, \\
t=1,2, \ldots, T, \\
x_{i j t} \in\{0,1\}, \quad i=1,2, \ldots, m ; j=1,2, \ldots, n ; t=1,2, \ldots, T .
\end{gathered}
$$

In the scene of shared parking, the shared parking spaces prefer the allocation scheme with high utilization rate. Therefore, the objective function is to maximize the efficiency of the shared parking spaces during the time period involved in the model, where $q_{t i}$ indicates whether the parking demanders $i$ and the shareable parking spaces have an intersection at the time $t$. In formulas (6) and (7), the value of $x_{i j t}$ is fixed by 0 or 1 , which means each parking request is assigned only one parking space at the time of $t$, where 0 means that $i$ is not allocated to the parking space $j$ at the time of $t$, and 1 means that the owner $i$ is allocated to the parking space at $j$ parking. Constraint (8) denotes the sharing time window, such as $d_{i j}=1$, meaning that the time of the vehicle does not match the parking space, $x_{i j t}=1$ means the owner $i$ is assigned to the parking space $j$, which does not match the former $j$ parking space time. Hence, the abovementioned two parameters $i$ and $j$ cannot be fixed at 1 simultaneously. Constraint (9) means that the same parking space cannot allow parking of two cars simultaneously, of which the same time period conflicts with each other. 


\section{Measuring Satisfaction Degrees of Parking Demanders and Suppliers}

The shared parking platform analyzes the previous parking data and counts the key factors affecting the parking space selection. The platform is divided into three forms, clear numbers, interval numbers, and language term preference, in terms of the different expression forms of the parking factors [23]. $C=\left\{C^{C}, C^{I}, C^{L}\right\}$ is the classified attribute set, $C^{C}, C^{I}, C^{L}$ represent clear numbers, interval numbers, and attribute set of language term preference, respectively. Firstly, the matching of the parking time period should be prioritized throughout the process of matching between parking demanders and parking spaces [24]. Secondly, an optimization model considering satisfaction is therefore established to complete the matching of parking demanders and shared parking spaces in accordance with the preference of the parking demanders for the parking space.

When the platform provides parking spaces to the parking demanders, whether the real evaluation level of each shared parking space reaches the aspiration level of parking demanders should be taken into serious consideration. Inasmuch as measuring the degree of the aspiration level, it is necessary to calculate the parking demanders satisfaction of each attribute, thereby obtaining the overall satisfaction degree regarding the weight of each attribute.

The following process of calculation describes the satisfaction degree with three formats of attribute values.

5.1. Calculation of Satisfaction Degree for the Attribute Value Type $C^{C}$. When $C_{g} \in C_{c}$, the attribute value $C_{g}$ including the expectation and evaluation level attributes is a clear number. Then, $e_{i g}=e_{i g}^{\prime}$ and $a_{j g}=a_{j g}^{\prime}$ indicate the expectation level of parking demanders and the evaluation level of parking spaces on shared parking platforms, respectively, where $e_{i g}^{\prime} \geq 0, a_{j g}^{\prime} \geq 0$. Hence, with regard to the attribute $C_{g}$, the satisfaction $u_{i j}^{g}$ of parking demanders $D_{i}$ to the shared parking space $P_{j}$ is calculated as follows:

For benefit attribute,

$$
u_{i j}^{g}= \begin{cases}\frac{a_{j g}^{\prime}-a_{g}^{\prime m}}{e_{i g}^{\prime}-a_{g}^{\prime m}}, & a_{g}^{\min } \leq a_{j g}^{\prime} \leq e_{i g}^{\prime}, \\ 1, & e_{i g}^{\prime} \leq a_{j g}^{\prime} \leq a_{g}^{\prime \max }, \\ & i=1,2, \ldots, m, j=1,2, \ldots, n, g=1,2, \ldots, q,\end{cases}
$$

for cost attribute,

$$
u_{i j}^{g}= \begin{cases}1, & a_{g}^{\prime m} \leq a_{j g}^{\prime} \leq e_{i g}^{\prime}, \\ \frac{a_{g}^{\prime m a x}-a_{j g}^{\prime}}{a_{g}^{\max }-e_{i g}^{\prime}} & e_{i g}^{\prime} \leq a_{j g}^{\prime} \leq a_{g}^{\max }, \\ & i=1,2, \ldots, m, j=1,2, \ldots, n, g=1,2, \ldots, q,\end{cases}
$$
where $\quad a_{g}^{\prime \min }=\min _{g}\left\{a_{j g}^{\prime}\right\}, a_{g}^{\prime \max }=\max _{g}\left\{a_{j g}^{\prime}\right\}, \quad j=1,2, \ldots$,
$n$.

\subsection{Calculation of Satisfaction Degree for the Attribute} Value Type $C^{I}$. When the attribute value type including the expectation level and the evaluation level attribute $C_{g}$ is an interval number. Then, $e_{i g}=\left(e_{i g}^{L}, e_{i g}^{R}\right)$ and $a_{j g}=\left(a_{j g}^{L}, a_{j g}^{R}\right)$ indicate the expectation level of parking demanders and the evaluation level of parking spaces on shared parking platforms, respectively, where $e_{i g}^{R} \geq e_{i g}^{L}, a_{j g}^{R} \geq a_{j g}^{L} \quad$ and $e_{i g}^{L} \geq 0, a_{j g}^{L} \geq 0$. Hence, with regard to the attribute $C_{g}$, the satisfaction $u_{i j}^{g}$ of parking demanders $D_{i}$ to the shared parking space $P_{j}$ is calculated as follows:

$$
u_{i j}^{g}= \begin{cases}\frac{a_{j g}-a_{g}^{\min }}{e_{i g}^{L}-a_{g}^{\min }}, & a_{g}^{\min } \leq a_{j g} \leq e_{i g}^{L}, \\ 1, & e_{i g}^{L} \leq a_{j g} \leq e_{i g}^{R}, \\ \frac{a_{g}^{\max }-a_{j g}}{a_{g}^{\max }-e_{i g}^{R}}, & e_{i g}^{R} \leq a_{j g} \leq a_{g}^{\max }, \\ & i=1,2, \ldots, m, j=1,2, \ldots, n, g=1,2, \ldots, q,\end{cases}
$$

where $a_{g}^{\min }=\min _{g}\left\{a_{j g}\right\}, a_{g}^{\max }=\max _{g}\left\{a_{j g}\right\}, \quad j=1,2, \ldots, n$.

5.3. Calculation of Satisfaction Degree for the Attribute Value Type $C^{L}$. If $C_{g} \in C^{L}$, the attribute value type including the expectation level and the evaluation level attribute is a 
language term. We suppose $O=\left\{O_{1}, O_{2}, \ldots O_{k}\right\}$ is a fully ordered set of language terms with an odd base, where $O_{k}$ is the $k$ language term in the collection $O$ and $k+1$ is the cardinality of the attribute set $O$. We assume $\alpha_{i g}$ is the subscript value of the linguistic term corresponding to the parking demanders' aspiration level $e_{i g}$ and presume $\beta_{j g}$ is the subscript value of the linguistic term corresponding to the shared parking platform evaluation level. Hence, with regard to the attribute $C_{g}$, the satisfaction $u_{i j}^{g}$ of parking demanders $D_{i}$ to the shared parking space $P_{j}$ is calculated as follows:

for benefit attribute,

for cost attribute,

$$
u_{i j}^{g}= \begin{cases}\frac{\beta_{j g}-\beta_{g}^{\min }}{\alpha_{i g}-\beta_{g}^{\min },} & \beta_{g}^{\min } \leq \beta_{j g} \leq \alpha_{i g}, \\ 1, \quad & \alpha_{i g} \leq \beta_{j g} \leq \beta_{g}^{\max }, \\ & i=1,2, \ldots, m, j=1,2, \ldots, n, g=1,2, \ldots, q, \\ & d_{i j}+x_{i j t} \leq 1, \quad i=1,2, \ldots, m ; j=1,2, \ldots, n ; t=1,2, \ldots, T,\end{cases}
$$

$$
u_{i j}^{g}= \begin{cases}1, & \beta_{g}^{\min } \leq \beta_{j g} \leq \alpha_{i g}, \\ \frac{\beta_{g}^{\max }-\beta_{j g}}{\beta_{g}^{\max }-\alpha_{i g}}, & \alpha_{i g} \leq \beta_{j g} \leq \beta_{g}^{\max }, \\ & i=1,2, \ldots, m, j=1,2, \ldots, n, g=1,2, \ldots, q,\end{cases}
$$

where $\beta_{g}^{\min }=\min _{g}\left\{\beta_{j g}\right\}, \beta_{g}^{\max }=\max _{g}\left\{\beta_{j g}\right\}, \quad j=1,2, \ldots, n$.

The overall satisfaction of the parking demanders to the shared parking space regarding satisfaction degree of each attribute $u_{i j}$ and the corresponding attribute weight $w_{g}$ is calculated as follows:

$$
u_{i j}=\sum_{g=1}^{q} w_{g} u_{i j}^{g}
$$

\section{Constructing the Optimization Matching Model}

Based on the principle of time matching and the satisfaction degree $u_{i j}$, the multiobjective optimization model $M 2$ for matching parking demanders and shared parking spaces is established as follows:

$$
\begin{aligned}
& \max z_{1}=\sum_{i=1}^{m} \sum_{j=1}^{n} \sum_{t=1}^{T}\left(q_{t i} x_{i j t}\right), \\
& \max z_{2}=\sum_{i=1}^{m} \sum_{j=1}^{n} \sum_{t=1}^{T}\left(u_{i j} x_{i j t}\right),
\end{aligned}
$$

$$
\text { s.t. } \quad \sum_{j=1}^{n} x_{i j t} \leq 1 \quad i=1,2, \ldots, m, t=1,2, \ldots, T \text {. }
$$

$$
\begin{array}{r}
x_{i j t}+p_{i r} x_{r j t} \leq 1, \quad i, r=1,2, \ldots, m ; j=1,2, \ldots, n ; \\
t=1,2, \ldots, T, \\
x_{i j t} \in\{0,1\}, \quad i=1,2, \ldots, m ; j=1,2, \ldots, n ; t=1,2, \ldots, T .
\end{array}
$$

The abovementioned model consists of two objective functions. The objective function (17) is to maximize the efficiency of the shared parking space, meaning that the time of each shared parking space is used as long as possible. The objective function (18) is to maximize the satisfaction of parking demanders. Formulas (19) to (22) are constraints, where constraint (19) ensures that each parking demander can only match at most one shared parking space and constraint (20) ensures that the time matching of shared parking spaces and parking demanders does not conflict to each other despite whether it is assigned to the parking space. Constraint (21) ensures that the same parking space cannot stop two vehicles at the same time.

\section{An Algorithm for Solving the Optimization Matching Model}

The model $M 2$ is a two-objective $0-1$ integer programming problem. As participants ( $m$ and $n$ ) increase, the solution of the model $M 2 a$ becomes very complicated. To deal with $M 2$ MODEL, this section proposes a solution algorithm based on the weighted sum method and the Hungarian algorithm, which [25] is used to convert the dual-objective optimization model M2 into a single-objective optimization model M3 by adopting the weighted sum method. Then, according to the single-objective optimization model $M 3$, a standard assignment model $M 4$ is built, which can be solved by the Hungarian method [26]. The result of the model $M 4$ is the noninferior solution of the two-objective optimization model M2. The specific solution process is as follows. 
Let $\alpha$ and $1-\alpha$ be the weights (importance degrees) of the objective functions $z_{1}$ and $z_{2}$, respectively, varying between 0 and 1 . Generally, they can be assigned by the shared parking platform or be assigned in terms of core competence theory [27] as follows:

$$
\left\{\begin{array}{l}
\alpha=\frac{|D|}{(|D|+|P|)}, \\
1-\alpha=\frac{|P|}{(|D|+|P|)},
\end{array}\right.
$$

where $|D|$ is the cardinality of set $D$. Besides, multiple values of $\alpha$ can be used to obtained multiple satisfied demander supply matching results, and then the shared parking platform can select one from the multiple satisfied demander supply matching results according to the practical requirements. According to the dual-target optimization model $M 2$, a single-objective optimization model $M 3$ that maximizes the satisfaction of parking demanders and parking spaces can be constructed:

$$
\begin{gathered}
\max z=\alpha \sum_{i=1}^{m} \sum_{j=1}^{n} \sum_{t=1}^{T}\left(q_{t i} x_{i j t}\right)+(1-\alpha) \sum_{i=1}^{m} \sum_{j=1}^{n} \sum_{t=1}^{T}\left(u_{i j} x_{i j t}\right) \\
\text { s.t. } \quad \sum_{j=1}^{n} x_{i j t} \leq 1 \\
\quad i=1,2, \ldots, m t=1,2, \ldots, T
\end{gathered}
$$$$
d_{i j}+x_{i j t} \leq 1, \quad i=1,2, \ldots, m ; j=1,2, \ldots, n ; t=1,2, \ldots, T,
$$

$$
\begin{aligned}
x_{i j t}+p_{i r} x_{r j t} \leq 1, \quad i, r=1,2, \ldots, m ; j & =1,2, \ldots, n \\
t & =1,2, \ldots, T
\end{aligned}
$$

$x_{i j t} \in\{0,1\}, \quad i=1,2, \ldots, m ; j=1,2, \ldots, n ; t=1,2, \ldots, T$

The parking demander can select a satisfactory parking space from the multiple matching results of the parking space-demander with regard to the difference of satisfaction between the two parties. Similarly, the shared parking space can also select a satisfactory demander from multiple matching demanders. The abovementioned analysis shows that the model M3 is a basic allocation model, which is transformed into a standard distribution model by adopting the Hungarian algorithm.

It is known that by the objective function of the model M3, $\quad z=\alpha \sum_{i=1}^{m} \sum_{j=1}^{n} \sum_{t=1}^{T}\left(q_{t i} x_{i j t}\right)+(1-\alpha) \sum_{i=1}^{m} \sum_{j=1}^{n}$ $\sum_{t=1}^{T}\left(u_{i j} x_{i j t}\right)=\sum_{i=1}^{m} \sum_{j=1}^{n} \sum_{t=1}^{T}\left[\alpha q_{t i}+(1-\alpha) u_{i j}\right] x_{i j t}$, where $\alpha q_{t i}+(1-\alpha) u_{i j}$ is the weighted satisfaction of the standard allocation model $M 3$. Therefore, let $V=\left[v_{i j}\right]_{m \times n}$ denote the weighted satisfaction degree matrix of the model $M 3$, where $v_{i j}$ represents the weighted satisfaction of the matching demander $i$ and the parking space $j$. The weighted satisfaction degree can be calculated by the following equation:

$$
v_{i j}= \begin{cases}\alpha q_{t i}+(1-\alpha) u_{i j}, & x_{i j t}=1, \\ 0, & x_{i j t} \neq 1, \\ & i=1,2, \ldots, m, j=1,2, \ldots, n .\end{cases}
$$

The objective of the Hungarian algorithm is to minimize the objective function. In order to establish a standard allocation model, it is necessary to convert the maximization problem into a minimization problem. In specific cases, the parking demander has only one parking demander in the matching cycle involved in the model, the parking space can be shared only one shareable time period and the number of parking demanders equals to the number of shared parking spaces, and the adoption of the Hungarian algorithm maximizing the problem can be directly translated into an equivalent of minimization problem. However, in reality, a person who seeks for parking may have multiple parking demanders. A shareable parking space may have multiple different shareable time periods. The number of parking demanders and shareable parking spaces may not be equal, which in turn generates the following method conducted in this paper.

Inasmuch as the principle of the Hungarian method in specific cases, we know that if there is a person who seeks for parking with multiple parking demanders within the period involved in the model, the demander is transformed into multiple demanders with the same preference but different parking periods. By converting parking demanders who are featured with multiple parking needs into parking demanders with only one parking requirement, $m$ parking demanders can therefore be converted into $m$ ' parking demanders, so $D^{\prime}=\left\{D_{1}, D_{2}, \ldots, D_{m}, \ldots, D_{m}\right\}$. Similarly, a shareable parking space with multiple shareable time periods is converted into multiple parking spaces with the same preference value but different sharing time periods, and each parking space has only one shareable time period. Therefore, $n$ parking spaces can be converted to $n$ ' parking spaces, then $P^{\prime}=\left\{P_{1}, P_{2}, \ldots, P_{n}, \ldots, P_{n_{1}}\right\}$. Let $b=\max \left\{m^{\prime}, n^{\prime}\right\}$, if the number of parking demanders and the number of shared parking spaces are different, setting virtual $b-m$ ' parking demanders or $b-n$ ' shareable parking spaces will turn the original matrix into a $b$ matrix. $D_{f}^{\prime}$ represents the first parking demander and $P_{h}^{\prime}$ represents the first shareable parking space. Therefore, $L=\left[l_{f h}\right]_{b \times b}$ represents the converted comprehensive satisfaction matrix. The specific solution process for converting a complex situation into a standard allocation model is as follows:

(1) Finding the maximum value of the initial comprehensive satisfaction $N$, then $N=\max$ $\left\{v_{i j} \mid i=1,2, \ldots m ; j=1,2, \ldots n\right\}$;

(2) Judging whether there is only one parking demander for a parking seeker, whether one shared 
parking space has only one shareable time period, and whether the value of these two factors equals to each other. If so, proceed to the third step. If not, convert the parking demanders and the shareable parking space to only one parking requirement and only one shareable time period, respectively. Setting $b-m \prime$ as virtual parking demanders or setting $b-n$ ' as shareable parking spaces. The original matrix becomes a $b$ order square matrix, and the weighted satisfaction of the virtual parking demanders or shareable parking space is 0 .

(3) The maximum value $N$ of the initial comprehensive satisfaction minus the remaining weighted satisfaction $v_{i j}$ and the converted cost value is $l_{f h}$.

$Y=\left[y_{f h}\right]_{b \times b}$ denotes the decision matrix. If $y_{f h}=1$, the equation indicates that the consumer $D_{j}^{\prime}$ matches the parking space $P_{h}^{\prime}$. If $y_{f h}=0$, it means other conditions. According to the cost matrix $L=\left[l_{f h}\right]_{b \times b}$ and the decision matrix $Y=\left[y_{f h}\right]_{b \times b}$, the standard allocation model $M 4$ can be constructed as follows:

$$
\begin{aligned}
& \min z^{\prime}=\sum_{f=1}^{b} \sum_{h=1}^{b} l_{f h} y_{f h}, \\
& \text { s.t. } \quad \sum_{h=1}^{b} y_{f h}=1, \quad f=1,2, \ldots, b, \\
& \sum_{f=1}^{b} y_{f h}=1, \quad h=1,2, \ldots, b, \\
& y_{f h} \in\{0,1\}, \quad f, h=1,2, \ldots, b .
\end{aligned}
$$

In the model $M 4$, the objective function of constraint (30) minimizes the overall opportunity cost. The constraint (31) ensures that a demander only matches a shareable parking space. The constraint (32) guarantees that a parking space can only be assigned to a demander. For the standard allocation model $M 4$, it can be solved by the Hungarian algorithm.

In summary, the matching problem solver proposed in this paper has 6 steps (as shown in Figure 2), which considers the maximum efficiency of shared parking spaces and maximizes the satisfaction of the owner.

$1^{\text {st }}$ step: matching supply and demand time. The shared parking platform receives demand information from the parking demander and the shared information from the shared parking space, respectively, thereby matching and building the model $M 1$ according to the supply and demand time.

$2^{\text {nd }}$ step: satisfaction calculation is performed. The parking demanders will submit the expectation level of each attribute of the shareable parking space to the platform. The platform generates the evaluation level of the shareable parking space in terms of the parking space information submitted by the owner of the shared parking space whereby the satisfaction of the demander is calculated.

$3^{\text {rd }}$ step: construction of a dual-objective model. A dualobjective optimization model $M 2$ that maximizes the utilization of the parking space and the satisfaction of the demander is constructed with the help of the supply and demand time matching model $M 1$ as well as the satisfaction of the demander.

$4^{\text {th }}$ step: transforming into a single-objective model. By adopting the weighted sum method, the dual-objective model M2 is transformed into a single-objective optimization model $M 3$ that maximizes the overall weighted satisfaction.

$5^{\text {th }}$ step: model standardization is done. Through conducting the specific cases of Hungarian algorithm, the transformation of the original model is therefore described as follows. A parking seeker has only one parking demand, a shareable parking slot has only one shareable time period, and the number of demanders and parking slots is the same.

$6^{\text {th }}$ step: establishing a standard allocation model. Transforming the maximization problem into a minimization problem. Establishing the standard allocation model M4 by adopting the Hungarian algorithm, thereby obtaining the distribution result.

\section{Numerical Experiments}

In this section, an example for shared parking is presented to illustrate the implementation of the proposed method. Simulations are performed to test the effectiveness and fairness of the proposed model and of the optimization algorithm, which is conducted by comparing with the first come first serve (FCFS) allocation method.

In order to verify the validity of the proposed model and the optimization algorithm (OA), the simulation experiment is designed according to the idle time characteristics of the parking space in the residential area and compared with the first come first serve (FCFS) allocation method (the result is shown in Figure 3). Taking the parking status of Xi'an for instance, we suppose $D=\left\{D_{1}, D_{2}, \ldots, D_{10}\right\}$ means 10 parking demanders (the detailed information is shown in Table 1) (this article takes 0.5 hours as an example). $P=$ $\left\{P_{1}, P_{2}, P_{3}, P_{4}, P_{5}\right\}$ means 5 shared parking spaces in 5 residential areas. The specific information is shown in Table 2.

The shared parking platform provides a level of shared parking space with five attributes, including unit parking cost $C_{1}$, time required for the vehicle to reach the parking space $C_{2}$, walking distance after parking $C_{3}$ (this article in meters), the safety of the parking space $C_{4}$, and the priority attribute $C_{5}$ (calculated by the historic transaction records, including convenience, confidence, and the surroundings of parking spots). The information of five shared parking spaces is shown in Table 3:

In Table $3, C_{1}, C_{2}$, and $C_{3}$ are quantitative attributes, and the satisfaction degree for $C_{1}$ and $C_{2}$ is expressed in the form of 1-10 points (1: very bad, 10: very good). Since the distance 


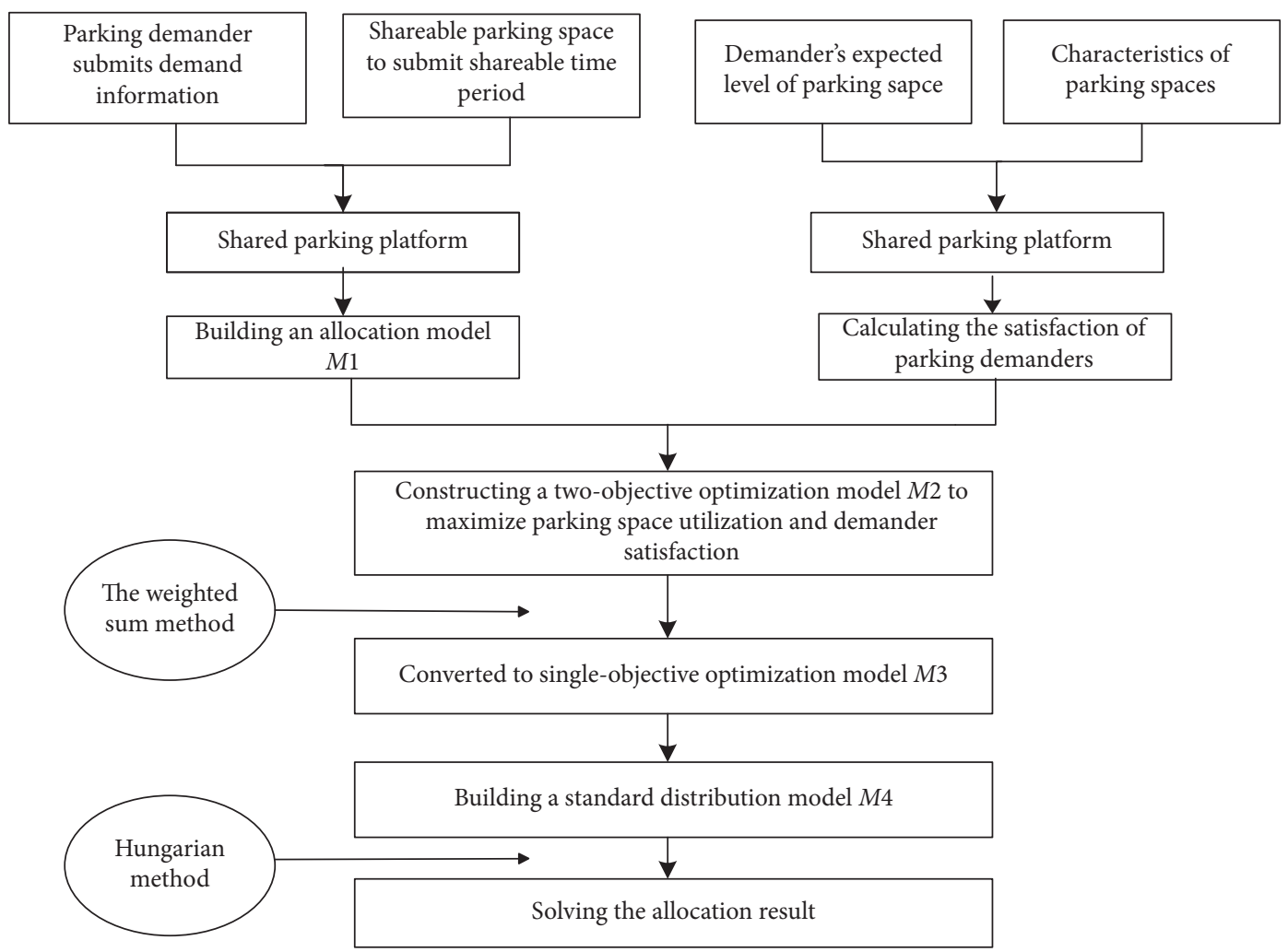

FIGURE 2: Matching method framework.

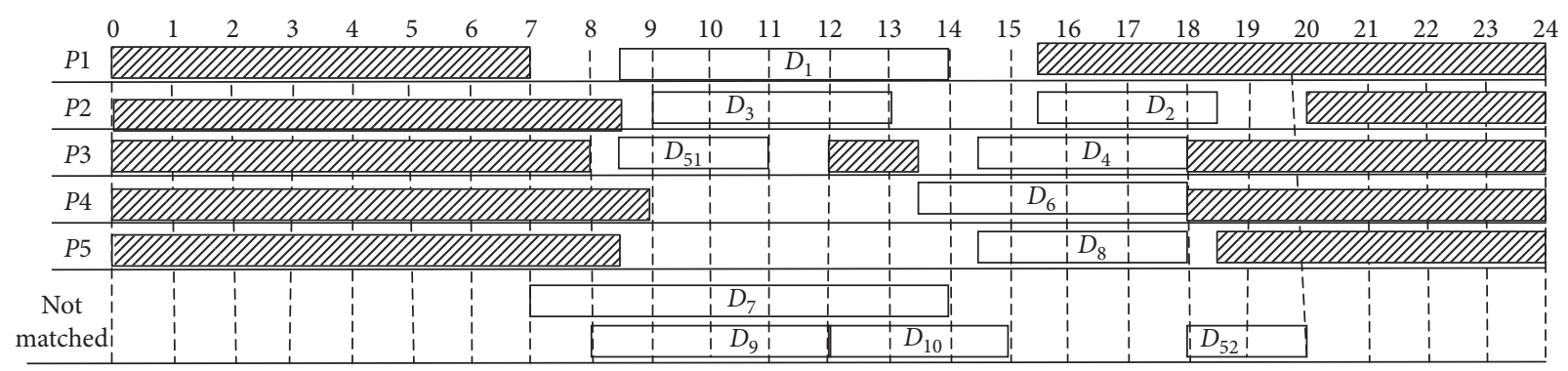

FIGURE 3: FCFS method assignment result.

Table 1: Parking seekers' time information.

\begin{tabular}{lccc}
\hline Parking seekers & Parking seekers period & Parking seekers & Parking seekers period \\
\hline$D_{1}$ & {$[8: 30,14: 00]$} & $D_{6}$ & {$[13: 30,18: 00]$} \\
$D_{2}$ & {$[15: 30,18: 30]$} & $D_{7}$ & {$[7: 00,14: 00]$} \\
$D_{3}$ & {$[9: 00,13: 00]$} & $D_{8}$ & {$[14: 30,18: 00]$} \\
$D_{4}$ & {$[14: 30,18: 00]$} & $D_{9}$ & {$[8: 00,12: 00]$} \\
$D_{5}$ & {$[8: 30,11: 00],[18: 00,20: 00]$} & $D_{10}$ & {$[12: 00,15: 00]$} \\
\hline
\end{tabular}

TABLE 2: Shared parking space sharing time information.

\begin{tabular}{lc}
\hline Shared parking space number & Parking space sharing time \\
\hline$P_{1}$ & {$[7: 00,15: 30]$} \\
$P_{2}$ & {$[8: 30,20: 00]$} \\
$P_{3}$ & {$[8: 00,12: 00],[13: 30,18: 00]$} \\
$P_{4}$ & {$[9: 00,18: 00]$} \\
$P_{5}$ & {$[8: 30,18: 30]$} \\
\hline
\end{tabular}

TABLE 3: Evaluation level of shared parking spaces.

\begin{tabular}{lccccc}
\hline Parking space/attribute & $C_{1}$ & $C_{2}$ & $C_{3}$ & $C_{4}$ & $C_{5}$ \\
\hline$P_{1}$ & 8 & 8 & 150 & $O_{3}$ & $O_{4}$ \\
$P_{2}$ & 9 & 8 & 220 & $O_{4}$ & $O_{5}$ \\
$P_{3}$ & 10 & 9 & 180 & $O_{3}$ & $O_{3}$ \\
$P_{4}$ & 8 & 10 & 290 & $O_{4}$ & $O_{3}$ \\
$P_{5}$ & 8 & 9 & 270 & $O_{4}$ & $O_{2}$ \\
\hline
\end{tabular}


TABLE 4: The demand level of parking seekers for shared parking spaces.

\begin{tabular}{lccccc}
\hline & $C_{1}$ & $C_{2}$ & $C_{3}$ & $C_{4}$ & $C_{5}$ \\
\hline$D_{1}$ & 7 & 8 & {$[280,300]$} & $O_{3}$ & $O_{4}$ \\
$D_{2}$ & 8 & 7 & {$[300,350]$} & $O_{5}$ & $O_{3}$ \\
$D_{3}$ & 9 & 8 & {$[250,290]$} & $O_{5}$ \\
$D_{4}$ & 8 & 9 & {$[270,330]$} & $O_{4}$ & $O_{3}$ \\
$D_{5}$ & 8 & 9 & {$[230,300]$} & $O_{3}$ & $O_{3}$ \\
$D_{6}$ & 10 & 9 & {$[300,340]$} & $O_{3}$ & $O_{3}$ \\
$D_{7}$ & 8 & 8 & {$[260,290]$} & $O_{5}$ & $O_{5}$ \\
$D_{8}$ & 9 & 9 & {$[230,350]$} & $O_{4}$ & $O_{3}$ \\
$D_{9}$ & 5 & 8 & {$[270,300]$} & $O_{3}$ \\
$D_{10}$ & 8 & 7 & & & $O_{3}$ \\
\hline
\end{tabular}

TABLE 5: Satisfaction of parking seekers with shared parking spaces.

\begin{tabular}{lccccc}
\hline & $P_{1}$ & $P_{2}$ & $P_{3}$ & $P_{4}$ & $P_{5}$ \\
\hline$D_{1}$ & 1 & 1 & 0.93 & 0.93 & 0.85 \\
$D_{2}$ & 0.85 & 1 & 0.85 & 0.85 \\
$D_{3}$ & 0.63 & 0.95 & 0.84 & 0.64 & 0.90 \\
$D_{4}$ & 0.56 & 0.72 & 0.79 & 0.93 & 0.85 \\
$D_{5}$ & 0.72 & 0.65 & 1 & 0.79 & 0.95 \\
$D_{6}$ & 0.51 & 0.62 & 1 & 0.74 & 0.64 \\
$D_{7}$ & 0.89 & 0.95 & 0.89 & 0.80 \\
$D_{8}$ & 0.35 & 0.67 & 0.79 & 0.90 & 0.59 \\
$D_{9}$ & 0.84 & 1 & 1 & 0.85 \\
$D_{10}$ & 1 & 1 & 0.85 \\
\hline
\end{tabular}

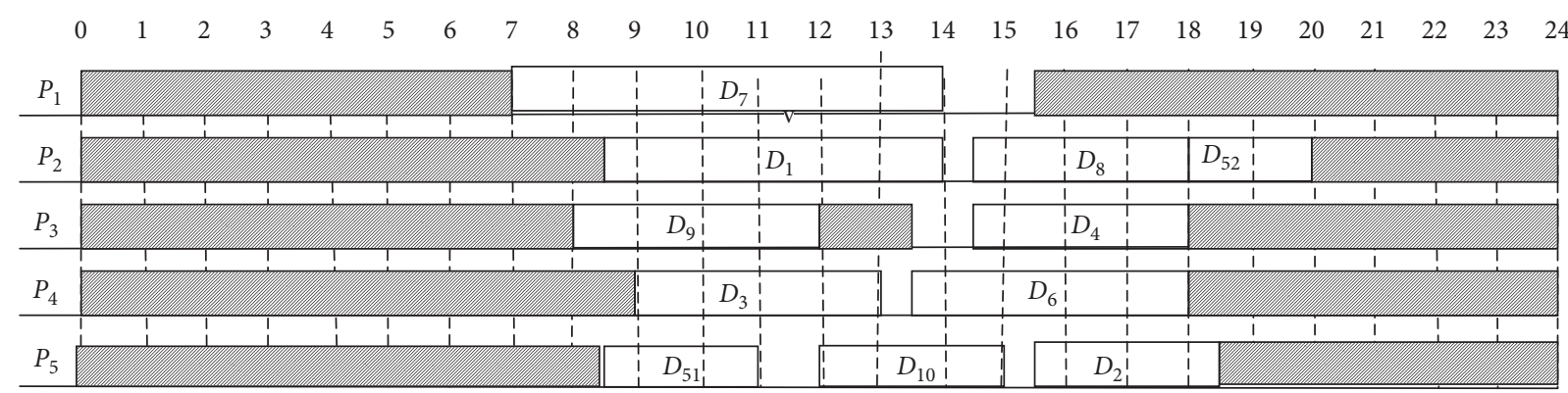

FIgURE 4: Optimizing the method assignment result.

of walking to the destination after parking is an estimated interval, the value of $C_{3}$ is the interval number form. $C_{4}, C_{5}$ attributes are qualitative attributes, where the values of $C_{4}$ and $C_{5}$ are in the format of linguistic terms in the 7granularity linguistic terms as follows: $O=\left\{\mathrm{O}_{0}=\right.$ absolutely poor, $\mathrm{O}_{1}=$ very poor, $\mathrm{O}_{2}=$ poor, $\mathrm{O}_{3}=$ medium, $\mathrm{O}_{4}=$ good, $\mathrm{O}_{5}=$ very good, $\mathrm{O}_{6}=$ absolutely good $\}$. As shown in Table 4, the parking demander displays the expectation level of the shareable parking space by five attributes of $C_{1}, C_{2}, C_{3}, C_{4}, C_{5}$. In real cases, the expectation value of the demander's walking distance after parking is $C_{3}$, which is expressed in intervals.

We assume that the shared parking platform uses AHP to determine the weight vector, where $w=(0.21$, $0.28,0.25,0.11,0.15)^{\mathrm{T}}$. The satisfaction level of the demander to the shared parking space can be calculated in terms of the evaluation level of the shared parking spaces in Table 3 and of the expected level of the demanders in Table 4 . The calculation results are shown in Table 5 .

In line with the rule of equality, we settle $\alpha=1-\alpha=0.5$. Considering the development stage of the shared parking platform, the weights can take different values. By adopting the weighting sum method and the Hungarian algorithm, the supply and demand data are input into the Lingo program for matching operation, thereby obtaining the optimal matching result between the demander and the parking space. The corresponding optimal allocation scheme is shown in Figure 4.

Comparing the abovementioned two results, two parking demanders are not allocated to the shareable parking space. The resource utilization rate stays low and the shared parking space does not reach its expected value in the 


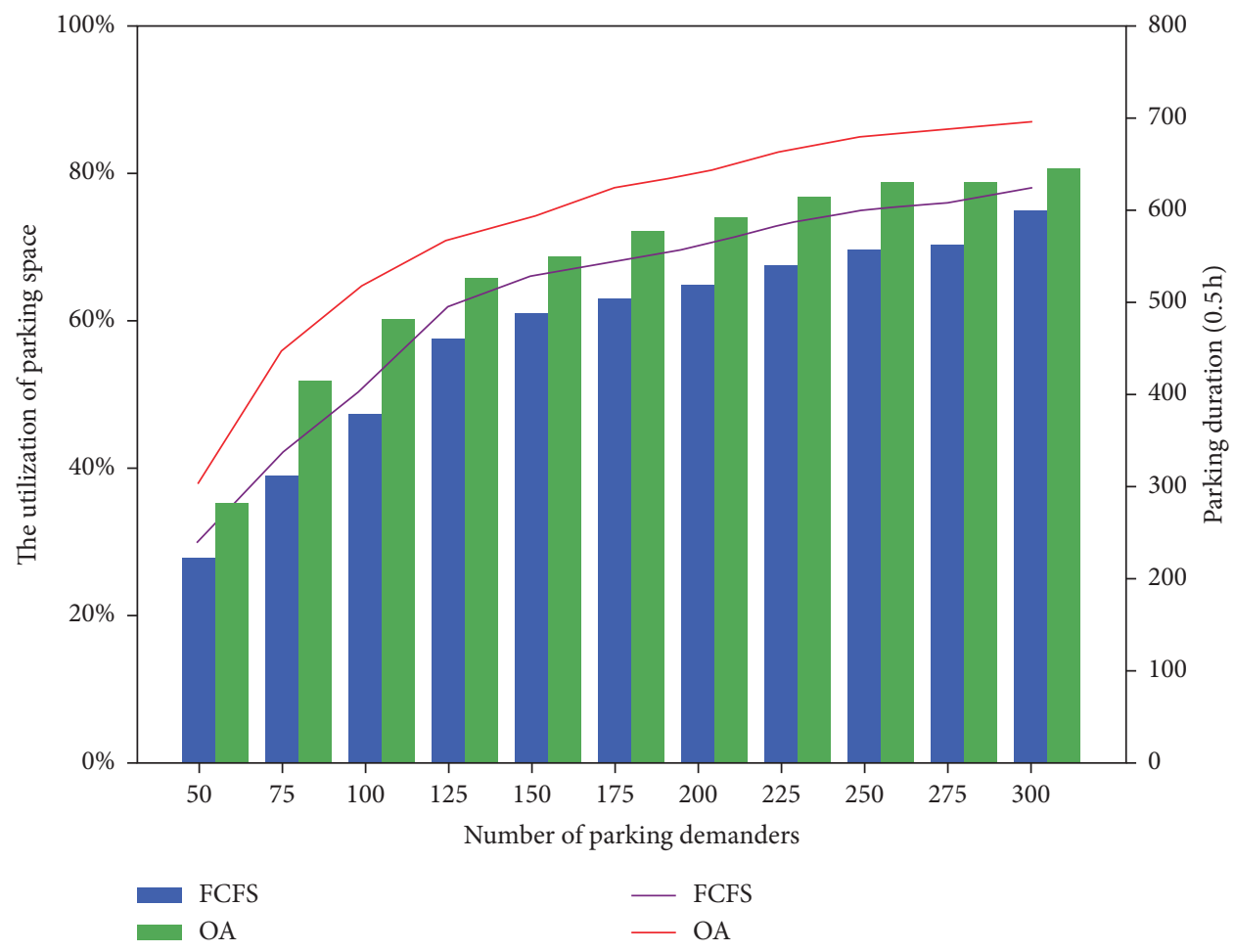

FIgURE 5: Comparison of parking utilization between FCFS and OA.

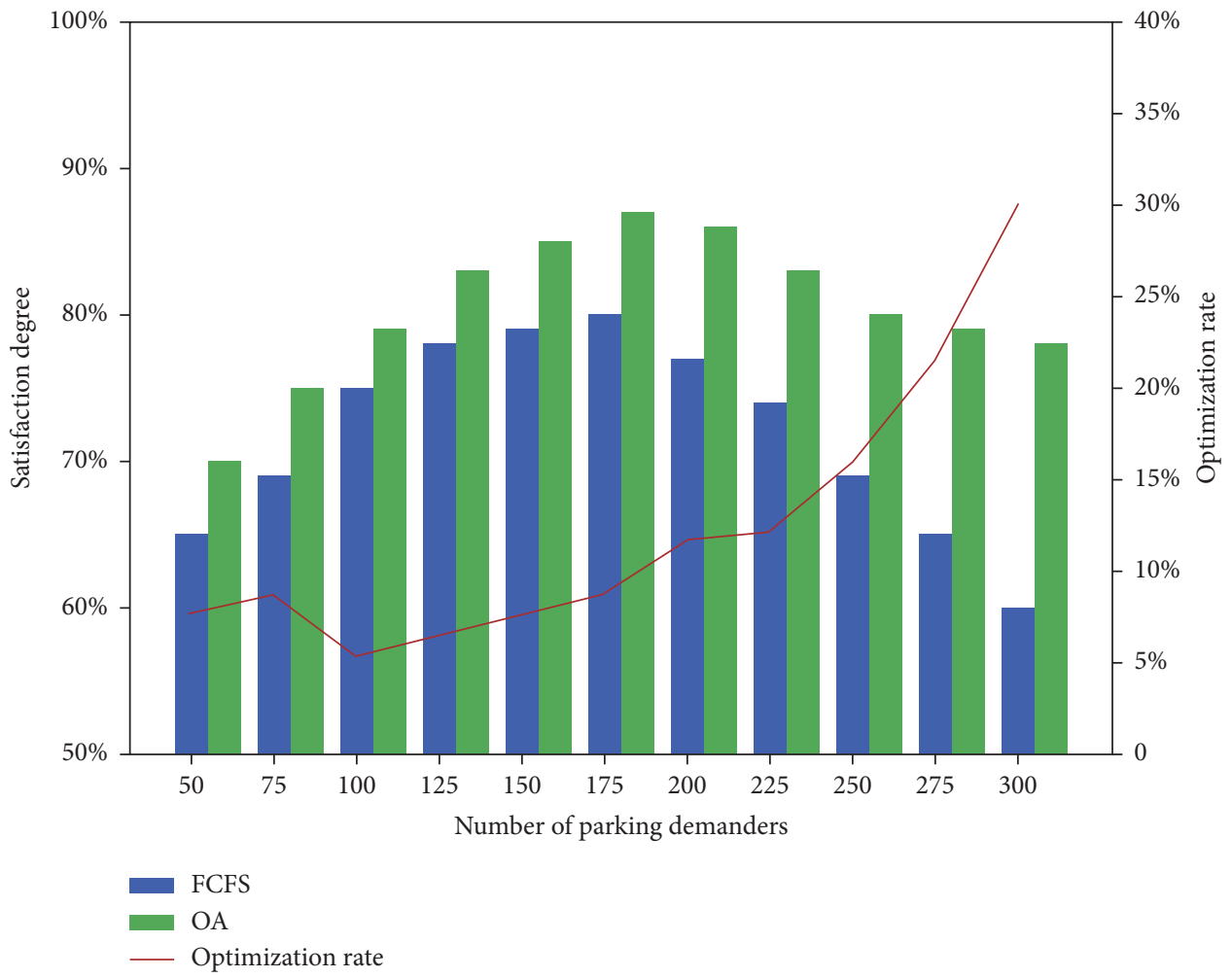

FIGURE 6: Comparison of parking satisfaction degree between FCFS and OA.

FCFS allocation scheme. Under the same supply and demand conditions, the shared parking space allocation scheme of the proposed paper can increase the parking space utilization time from $26 \mathrm{~h}$ to $42 \mathrm{~h}$, and the parking space utilization rate is increased by $33.68 \%$. The satisfaction level is increased from $55.64 \%$ to $79.73 \%$, and the parking 
satisfaction is increased by $24.09 \%$, which meet the requirements of the practical applications.

To further evaluate the feasibility and applicability of the optimization model, simulation experiments are performed between the proposed method and the FCFS allocation method. We suppose the modeling time interval is $0.5 \mathrm{~h}$ and the modeling period is $12 \mathrm{~h}$ starting from 8:00 AM and ending at 8:00 PM on a typical day. In the basic case, we suppose that a total number of shared parking lots is 100 . Furthermore, we suppose that, in any minute during the whole modeling period, the arrival of the parking demander follows a Poisson distribution and parking duration follows a negative exponential distribution, as usually considered in the literature $[28,29]$. The utilization efficiency of a parking lot is the ratio of the allocated total periods to the total periods provided by the parking space. The optimization rate of satisfactory degree is the ratio of difference between FCFS and the optimization algorithm (OA) to the satisfactory of FCFS. The environment is based on Python language. The test was repeated 30 times, and the experimental results are shown in Figures 5 and 6.

Simulation results showed that, under same conditions, the matching results of the shared parking space model and the algorithm adopted far outweighed the FCFS allocation method. These findings help the shared parking platform set better targeted policies to optimize indicators involving the parking utilization rate and total preference of the whole system, making breakthroughs in shared parking applications as well as in figuring out the satisfactory solution of parking allocations.

\section{Conclusions}

As a novel approach alleviating difficulties in car parking in terms of the scarcity of spaces amid urban environment, shared parking has proven an effective mechanism as one of the cornerstones in shared economy. To realize full use of the shared private-owned parking slots and to improve the satisfaction of both demander and supplier sides, this paper presents a novel method determining the satisfied matching between shared parking spaces and parking demanders. Firstly, a time matching model regarding supply and demand is built. Secondly, the preference is divided into three forms by the shared parking platform with regard to the different expressions of the parking preference, through which an optimization model considering the satisfaction degree is therefore constructed and an algorithm is accordingly designed. Thirdly, the superiority of the proposed model is verified and validated by comparing it with the first come first served (FCFS) strategy.

The model is ready to be applied to the shared parking system of Xi'an. The parking space allocation model of this paper is based on the known demand period of the parking demanders and the sharable time of the shared parking space. In reality, the demand of the parking demanders and the shareable time of the shared parking space are changing dynamically. The model can be further extended by considering the priority attributes of demanders and the dynamic matching between the supply and demanders considering bilateral preference, which will be the future interest of our research works.

\section{Data Availability}

The data used to support the findings of this study are available from the corresponding author upon request.

\section{Conflicts of Interest}

The authors declare no conflicts of interest.

\section{Acknowledgments}

This study was financially supported by the National Social Science Foundation of China (Grant number. 15BGL040).

\section{References}

[1] C. L. Cao, "Measuring sustainable development efficiency of urban logistics industry," Mathematical Problems in Engineering, vol. 2018, Article ID 9187541, 9 pages, 2018.

[2] Z. Peng, Y. Wang, and Q. Chen, "The generation and development of road rage incidents caused by aberrant overtaking: an analysis of cases in China," Transportation Research Part F: Traffic Psychology and Behaviour, vol. 60, pp. 606-619, 2019.

[3] C. G. Network, "The first half of 2019, the number of motor vehicles in the country reached 340 million," 2019, http://www. mot.gov.cn/guowuyuanxinxi/201907/t20190704_3221036.html.

[4] Beijing Transportation Development and Research Center, "Beijing traffic development annual report," Beijing Transportation Development and Research Center, Beijing, China, 2019, http://mini.eastday.com/a/190801063939079.html.

[5] C. Lei and Y. Ouyang, "Dynamic pricing and reservation for intelligent urban parking management," Transportation Research Part C: Emerging Technologies, vol. 77, pp. 226-244, 2017.

[6] A. J. Pel and E. Chaniotakis, "Stochastic user equilibrium traffic assignment with equilibrated parking search routes," Transportation Research Part B: Methodological, vol. 101, pp. 123-139, 2017.

[7] T. Zou, Y. K. Su, and Y. W. Wang, "Research on the hybrid ANP-FCE approach of urban community sustainable construction problem," Mathematical Problems in Engineering, vol. 2018, Article ID 8572498, 10 pages, 2018.

[8] Q. Chen, J. Yi, and Y. Wu, "Cellular automaton simulation of vehicles in the contraflow left-turn lane at signalised intersections," IET Intelligent Transport Systems, vol. 13, no. 7, pp. 1164-1172, 2019.

[9] Y. Can, C. Qun, and C. Lu, "Modeling and simulation of following behaviors of pedestrians under limited visibility," Acta Physica Sinica, vol. 68, no. 24, pp. 87-101, 2019.

[10] M. Yu and T. Li, "Information sharing in a supply chain under cap-and-trade regulation," Mathematical Problems in Engineering, vol. 2018, Article ID 4573919, 18 pages, 2018.

[11] S. X. Xu, M. Cheng, X. T. R. Kong, H. Yang, and G. Q. Huang, "Private parking slot sharing," Transportation Research Part B: Methodological, vol. 93, pp. 596-617, 2016.

[12] B. Yang, "The study on allocation model of shared parking slots in multi-parking lots," in Proceedings of the 2017 5th International Conference on Mechatronics, Materials, Chemistry and Computer Engineering, pp. 457-465, Chongqing, China, July 2017.

[13] H. Stin and J. Resha, Shared Parking Handbook, Stein Engineering, Beaverton, OR, USA, 1997. 
[14] W. Liu, H. Yang, Y. Yin, and F. Zhang, "A novel permit scheme for managing parking competition and bottleneck congestion," Transportation Research Part C: Emerging Technologies, vol. 44, p. 44, 2014.

[15] H. Xiao and M. Xu, "How to restrain participants opt out in shared parking market? a fair recurrent double auction approach," Transportation Research Part C: Emerging Technologies, vol. 93, pp. 36-61, 2018.

[16] S. Pan, Z. Liang, and Q. Chen, "When will car owners abandon car driving? analysis based on a survey of the parking experiences of people in Changsha, China," International Journal of Modern Physics B, vol. 33, no. 15, p. 1950148, 2019.

[17] C. Shao, H. Yang, Y. Zhang, and J. Ke, "A simple reservation and allocation model of shared parking lots," Transportation Research Part C: Emerging Technologies, vol. 71, pp. 303-312, 2016.

[18] Y. Cai, J. Chen, C. Zhang, and B. Wang, "A parking space allocation method to make a shared parking strategy for appertaining parking lots of public buildings," Sustainability, vol. 11, no. 1, 2018.

[19] X. T. R. Kong, S. X. Xu, M. Cheng, and G. Q. Huang, "IoTenabled parking space sharing and allocation mechanisms," IEEE Transactions on Automation Science and Engineering, vol. 15, no. 4, pp. 1654-1664, 2018.

[20] J. Hao, J. Chen, and Q. Chen, "Floating charge method based on shared parking," Sustainability, vol. 11, no. 1, 2019.

[21] W. Liu, H. Yang, and Y. Yin, "Expirable parking reservations for managing morning commute with parking space constraints," Transportation Research Part C: Emerging Technologies, vol. 44, pp. 185-201, 2014.

[22] M. Z. Duan, "Parking spaces allocation model of residential areas sharing parking based on personalized guidance," 2017.

[23] X. Chen, L. Zhao, H. Liang, and K. K. Lai, "Matching patients and healthcare service providers: a novel two-stage method based on knowledge rules and OWA-NSGA-II algorithm," Journal of Combinatorial Optimization, vol. 37, no. 1, pp. 221-247, 2019.

[24] X. Chen, Z. Li, Z.-P. Fan, X. Zhou, and X. Zhang, "Matching demanders and suppliers in knowledge service: a method based on fuzzy axiomatic design," Information Sciences, vol. 346-347, pp. 130-145, 2016.

[25] A. Charnes and W. W. Cooper, "Goal programming and multiple objective optimizations," European Journal of Operational Research, vol. 1, no. 1, pp. 39-54, 1977.

[26] H. W. Kuhn, "The Hungarian method for the assignment problem," Naval Research Logistics Quarterly, vol. 2, no. 1, pp. 83-97, 2015.

[27] C. Lawson, "Towards a competence theory of the region," Cambridge Journal of Economics, vol. 23, no. 2, pp. 151-166, 1999.

[28] D. E. Cleveland, "Accuracy of the periodic check parking study," Traffic Engineering, vol. 33, no. 12, pp. 14-17, 1963.

[29] A. Richardson, "An improved parking duration study method," in Proceedings of the Australian Road Research Board (ARRB) Conference, vol. 7, Adelaide, Australia, 1974. 